\title{
Climate trends and impacts on crop production in the Koshi River basin of Nepal
}

\author{
Dinesh Bhatt • Shreedhar Maskey • Mukand S. Babel • \\ Stefan Uhlenbrook • Krishna C. Prasad
}

Received: 12 June 2013/Accepted: 14 December 2013/Published online: 25 December 2013

(C) The Author(s) 2013. This article is published with open access at Springerlink.com

\begin{abstract}
Understanding crop responses to climate is essential to cope with anticipated changes in temperature and precipitation. We investigated the climate-crop yield relationship and the impact of historical climate on yields of rice, maize and wheat in the Koshi basin of Nepal. The results show significant impact of growing season temperature and precipitation on crop production in the region. Rice, maize and wheat cultivated at altitudes below 1,100, 1,350 and $1,700 \mathrm{~m}$ amsl (above mean sea level), respectively, suffer from stress due to higher temperatures particularly during flowering and yield formation stages. Responses of crop yields to a unitary increment in growing season mean temperature vary from -6 to $16 \%,-4$ to $11 \%$ and -12 to $3 \%$ for rice, maize and wheat, respectively, depending on the location and elevation in the basin. In most parts of the basin, we observe warming trends in growing season mean temperatures of rice, maize and wheat over the last few decades with clear evidence of negative impacts on yields. However,
\end{abstract}

Electronic supplementary material The online version of this article (doi:10.1007/s10113-013-0576-6) contains supplementary material, which is available to authorized users.

D. Bhatt $\cdot$ S. Maskey $(\bowtie) \cdot$ S. Uhlenbrook $\cdot$ K. C. Prasad

UNESCO-IHE Institute for Water Education,

P. O. Box 3015, 2601 DA Delft, The Netherlands

e-mail: s.maskey@unesco-ihe.org

D. Bhatt

Department of Irrigation, Jawalakhel, Lalitpur, Nepal

M. S. Babel

Asian Institute of Technology, P. O. Box 4,

Klong Luang 12120, Pathumthani, Thailand

S. Uhlenbrook

Delft University of Technology, P. O. Box 5048,

2600 GA Delft, The Netherlands at some high-elevation areas, positive impacts of warming are also observed on rice and maize yields. If the observed trends in temperature continue in future, the impact is likely to be mostly negative on crop production in the basin. However, crop production may gain from the warming at relatively higher altitudes provided other conditions, e.g., water availability, soil fertility, are favorable.

Keywords Climate trend - Crop yield $\cdot$ Koshi basin

\section{Introduction}

Potential impacts of climate change on crop production have received immense attention over the last decades (e.g., Parry et al. 2004; Tao et al. 2008). Understanding the relationship between climate and crop yield is fundamental to identify possible impacts of future climate and to develop adaptation measures. Moreover, evaluating the impacts of historic climate trends on crop production helps to assess the possible impacts of future climate, review the ongoing efforts of adaptation and assess the resulting change in production (Lobell and Field 2007; Lobell et al. 2011). The global average temperature has increased by about $0.13{ }^{\circ} \mathrm{C}$ per decade since 1950 (IPCC 2007a). Significant warming trends in the Himalayan and Tibetan regions, generally higher than the global average, are reported in the literature (Shrestha et al. 1999; Hu et al. 2011, 2013). Furthermore, the rate of warming is generally larger at the higher elevation (Sharma et al. 2009; Hu et al. 2013). Such warming trends in the world's largest and highest mountain system will obviously influence the glacier and snow dynamics, leading to changes in water resources availability, particularly during spring and autumn (Maskey et al. 2011). 
Several studies have estimated the likely impacts of future climate on crop production (Rosenzweig and Iglesias 1994; Arnell et al. 2002; Parry et al. 2004; Luo et al. 2009; Tao and Zhang 2010; Babel et al. 2011; Berg et al. 2012). However, the impacts on crop production due to historic climate trend are yet to be widely studied (Lobell and Field 2007), which is also true for the Koshi basin in the Himalaya region. The poor and vulnerable members of society have to face extra burden from climate change (IPCC 2007b). In the developing countries where subsistence farming is dominant, the impact of climate change is often locally specific and hard to predict (Morton 2007). The relationships between climate and crop yields are generally scale dependent (Tao et al. 2008). Therefore, examining the nature of the relationships on a finer spatial scale is essential to properly assess the impacts of climate change and to instigate suitable adaptation measures. Most studies reported in the literature are on coarser spatial resolution, often on global, regional and nation scales (e.g., Parry et al. 2004; Lobell and Field 2007; Rowhani et al. 2011; Lobell et al. 2011).

Small-scale, traditional and subsistence-oriented agriculture is the mainstay of Nepal's economy, which contributes about $39 \%$ to gross domestic product (GDP) and employs nearly $75 \%$ of country's work force. Although such a large portion of population is into agriculture, about $60 \%$ of the households are yet not able to meet their food needs, particularly in high-elevation areas (NARC 2010) and merely $13 \%$ of outputs are traded in markets (World Bank 2009). About $65 \%$ of the total cultivated land in Nepal is rain fed (Sharma and Khanal 2010), making the prevailing agriculture systems highly climate sensitive. Thus, the influence of climate on major crops often shapes the food security situation at the national and sub-national levels.

The main impetus of this study is to examine the climatecrop relationships and to investigate the impact of historic climate trends on rice, maize and wheat yields in the Koshi River basin. The Koshi basin is a Himalayan river basin of Nepal and a major sub-basin of the Ganges. More specifically, for all three crops (rice, maize and wheat), we examined the correlation between crop yields and growing season temperature and precipitation at a monthly time step, estimated trends of the growing seasons temperature and precipitation from observed time series and quantified the impacts of the trends on crop yields. We also estimated crop-specific favorable thresholds of minimum, maximum and mean temperature.

\section{Materials and methods}

Study area

Nepal is broadly divided into three agro-ecological zones: Terai (from Indo-Gangetic Plains up to $800 \mathrm{~m}$ altitudes), mid-hills (800-1,800 m) and high hills (above 1,800 m). Terai, where about $38 \%$ of the land is cultivated, covers $23 \%$ of the total geographic area of the country, i.e., $147,181 \mathrm{~km}^{2}$. Mid-hills, where $15 \%$ of the land is cultivated, constitutes the highest percentage (42\%) of the total geographic area. Similarly, high hills covers $35 \%$ of the total geographic area, and only $4 \%$ of the land is used for cultivation (Paudyal et al. 2001). Rice, maize and wheat are the most dominant crops of Nepal and cover 45, 20 and $18 \%$ of the total cultivated area, respectively (Gautam 2008). For rice, single cropping is feasible up to the elevation of 2,200 m amsl, while double cropping is generally limited to areas below 1,000 m amsl (Manandhar and Shakya 1996). Maize can be successfully cultivated at altitudes up to 2,800 $\mathrm{m}$ amsl in Nepal (Haffner 1984). However, in practice, maize cultivation is largely limited to $2,500 \mathrm{~m}$ amsl. Wheat is cultivated up to altitudes of 3,000 m amsl.

The Koshi basin is located in the latitudes between $26^{\circ} 51^{\prime}$ and $29^{\circ} 79^{\prime} \mathrm{N}$ and longitudes between $85^{\circ} 24^{\prime}$ and $88^{\circ} 57^{\prime} \mathrm{E}$. Altitudes of the districts (administrative boundaries of Nepal) within the basin range from about $100 \mathrm{~m}$ to above $8,000 \mathrm{~m}$ amsl including the Mt. Everest at $8,848 \mathrm{~m}$ amsl (Fig. 1). The basin covers six geological and climatic belts ranging from tropical in the Terai and low valleys to arctic on high hills. Moreover, the basin is ecologically and topographically diverse and covers all the three (Terai, mid-hills and high hills) agro-ecological zones of Nepal. Temperature varies considerably in the region according to elevation (Fig. S1). A large part of the Koshi basin in Nepal (south of the Himalayan range) receives an average annual precipitation of about 1,800 $\mathrm{mm}$ (estimated from the precipitation data used in this study). Average annual potential evapotranspiration (PET) of the basin is about 1,100 mm (estimated using the Hargreaves method). Rainfall is intense during the monsoon (June to September) with large local variation because of orographic effects.

\section{Data}

We obtained annual crop production data and cultivated areas for rice, maize and wheat from 1967 to 2008 at the district level from the Department of Agriculture (DOA), Nepal, for all 15 districts of the Koshi basin. These data are based on a systematic sampling procedure and validated through different field verification techniques, normally through joint field visits from the Ministry of Agriculture and Cooperative (MOAC), Department of Agriculture (DOA), Food and Agriculture Organization (FAO) and World Food Program (WFP) (K. Gautam, Personal communication, August 2012). The average crop production at the district level is estimated based on the sampling crop cut survey of representative samples (plots with average 
Fig. 1 Elevation range (m amsl) and meteorological stations in the districts of the Koshi basin, Nepal. The black line in the north is the border between Nepal and China. All other black lines are administrative boundaries of districts of Nepal. The part of the Koshi basin in China is not shown in the map

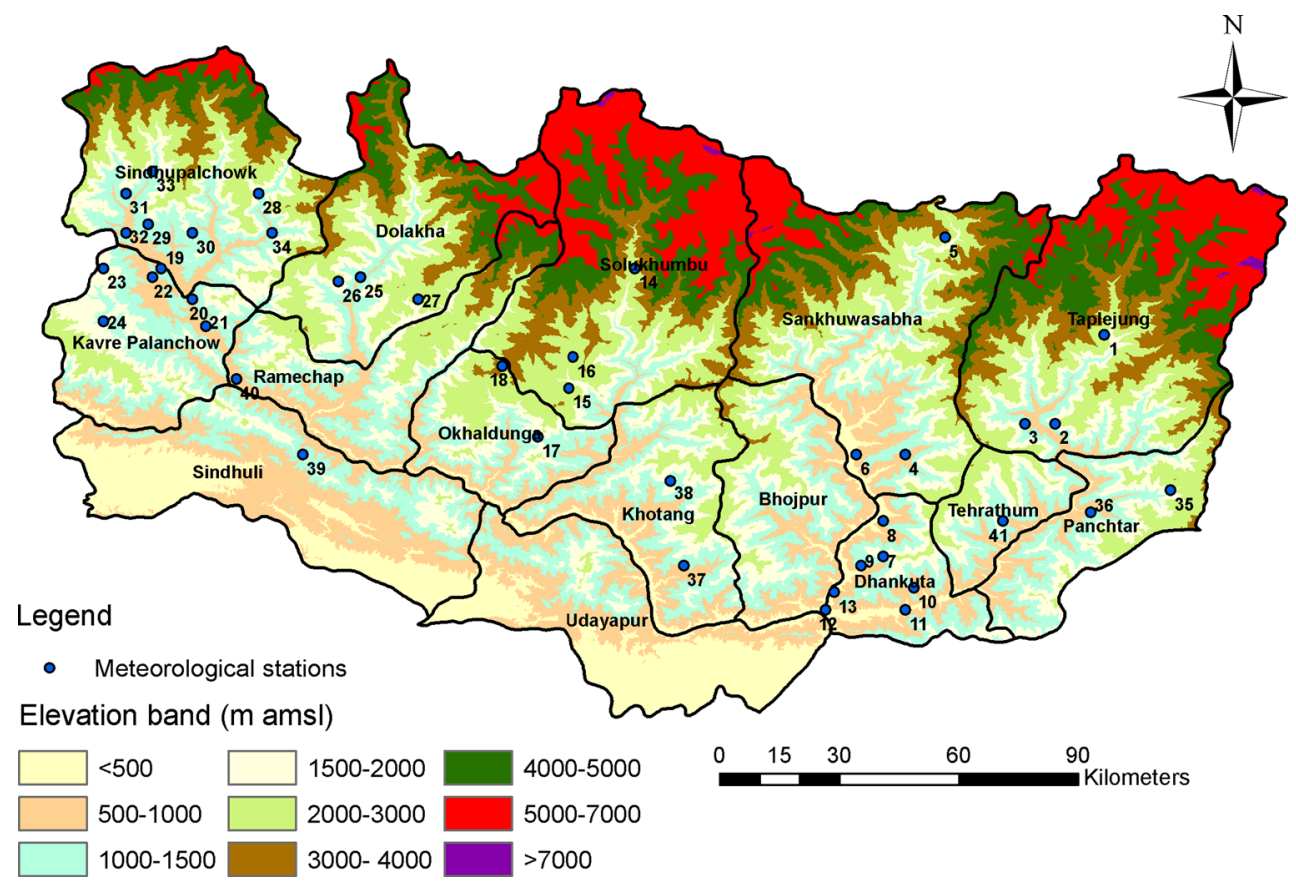

productivity). For each crop, minimum of 25-30 sample areas are used in each district. Regular supervision and monitoring are the main tools for controlling the quality of the survey data.

Temperature and precipitation time-series data were obtained from the Department of Hydrology and Meteorology (DHM), Nepal. These include daily minimum and maximum temperature from 11 stations with elevations ranging from 865 to $2,163 \mathrm{~m}$ amsl and precipitation from 41 stations with elevations ranging from 143 to $2,619 \mathrm{~m}$ amsl. The lengths of these data vary from 42 years (1967-2008) to 15 years (1994-2008). More information about the meteorological stations used is presented in Fig. 1 and Table S1.

\section{Methods}

\section{Climate-crop yield relationship}

Typical growing seasons (rounded to whole month) and growth stages for rice, maize and wheat in the region were taken from the relevant literature (Ghimire et al. 2011; Paudyal et al. 2001; Nayava et al. 2009). The growing season months used here are July to November for rice, March to August for maize and November to April for wheat. To examine the climate-yield relationship, we used a common approach (Nicholls 1997; Lobell et al. 2005; Lobell and Field 2007) based on the first-difference time series of yield and climate (precipitation, maximum, minimum and mean temperature) to minimize the confounding influence of long-term variations such as better seeds, fertilizers, pesticides, crop management, etc. The relations between de-trended crop yields and monthly temperatures (maximum, minimum and mean) and precipitation during the growing season were evaluated using the Pearson correlation analysis. In this evaluation, we excluded the climate data of the stations with altitude higher than the upper limit of the range of successful crop cultivation.

Pearson correlation coefficients between the growing season temperature (maximum, minimum and mean) and yield were also used to define a threshold temperature, which is a temperature above which crop yields are negatively correlated with temperature. We used Student's $t$ test to test an alternative hypothesis (i.e., negative/positive correlation between yield and temperature above/below the hypothesized threshold) against the null hypothesis (no correlation between yield and temperature) at $95 \%$ significance level. Anomalies of growing season temperatures from the estimated thresholds were used to evaluate the crop yield response to the historic temperature regimes.

\section{Impact of historic climate trends on crop yield}

The impact of climate trends (growing season mean temperature and monthly precipitation) on the crop yield was estimated following a commonly used approach (e.g., Lobell et al. 2011), which is based on multiple regression analysis of historical data. Multiple regression models for each district include temperature, precipitation, quadratic term for temperature and precipitation and district-specific time trends. The inclusion of quadratic terms accounts for the hill-shaped relation between climatic variables and crop 
yields (i.e., crops perform the best at certain optimal range of temperature and precipitation). Similarly, the districtspecific time trends account for changes in crop yields due to non-climatic variables and other technological developments. The model is of the form:

$\log \left(Y_{i, t}\right)=$ Constant $+\alpha_{i} *$ year $+\beta * X_{i, t}$

where $Y$ is a vector of crop yields, $\alpha_{i}$ is the linear time trend (spatially variable), $\beta$ is a vector of regression coefficients and $X$ is a vector of variables $\left(T, T^{2}, P\right.$ and $P^{2}$, where $T$ and $P$ are temperature and precipitation, respectively). We used the logarithmic form of the yield, $\log (Y)$, because crop yields follow a log-normal distribution and logarithmic transformation generally results in a more normally distributed variable (Lobell et al. 2011). The regression models were established between crop yields and four scenarios of temperature and precipitation: (I) actual temperature and actual precipitation, (II) de-trended temperature and de-trended precipitation, (III) de-trended temperature and actual precipitation and (IV) actual temperature and de-trended precipitation. Then, the impacts on crop yields due to the observed trends in both temperature and precipitation, in temperature only and in precipitation only were estimated as the trends in the difference between scenario (I) and scenario (II), scenario (I) and scenario (III), and scenario (I) and scenario (IV), respectively.

\section{Results and discussion}

Temperature-crop yield relationship

The correlations between the crop yield and growing season monthly mean temperature and monthly precipitation for rice, maize and wheat at different elevation ranges are presented in Fig. 2. The results show a number of statistically significant correlations between crop yields and monthly temperature and precipitation during growing seasons.

\section{Rice}

Mostly positive but weak correlations are observed between the mean monthly temperature and rice yield during the flowering and ripening stage (October and November). During the vegetative stage (July-September), the correlations are dominantly negative and are particularly pronounced in the elevation range between 1,300 and $1,700 \mathrm{~m}$. Generally, the rice yield is more strongly correlated with maximum temperature than the minimum temperature. We did not observe any distinct trends in the temperature-rice yield relationship with longitudes (EastWest). Regression between de-trended yield and temperature indicated that change in yields (compared with the yield of 2008) for a unit change in growing season maximum, minimum and mean temperatures in the basin ranged from -7 to $4 \%,-9$ to $11 \%$ and -6 to $16 \%$, respectively, depending on the locations and elevations of the area. In most cases, positive increments $\left(1{ }^{\circ} \mathrm{C}\right.$ rise $)$ in growing season minimum and mean temperatures show positive impacts on rice yields, whereas negative impacts are observed in most cases with a positive increment in maximum temperature (Fig. 3). We also identified temperature thresholds of $29^{\circ} \mathrm{C}$ (monthly maximum temperature), $21{ }^{\circ} \mathrm{C}$ (monthly mean temperature) and $19^{\circ} \mathrm{C}$ (monthly minimum temperature) using the $t$ test above which the rice yield is negatively correlated with temperature (Fig. 4). These temperature thresholds are in the range confirmed by other experimental studies (Baker and Allen 1993; Boote et al. 2005). Baker and Allen (1993) also indicated decline in rice yield by $10 \%$ for each degree rise in day temperature above $28{ }^{\circ} \mathrm{C}$ and night temperature above $21^{\circ} \mathrm{C}$. Similarly, Peng et al. (2004) indicated considerable reduction in the rice yield with the increase in nighttime temperature during the growing season above $22{ }^{\circ} \mathrm{C}$. The growing season minimum temperature remained fairly below the threshold of $21^{\circ} \mathrm{C}$ throughout the elevation range of $800-2,000 \mathrm{~m}$. This indicates that an increase in the nighttime temperature during the growing season up to the favorable threshold of $19{ }^{\circ} \mathrm{C}$ is likely to enhance rice production in the region. However, growing season mean and maximum temperature are above the estimated favorable threshold in the area below 1,000 and $1,500 \mathrm{~m}$ amsl, respectively.

\section{Maize}

Maize yields are mostly positively correlated with the mean temperature in the months of March and April which correspond to the establishment and vegetative stages. On the other hand, negative correlations are observed in the months of July (yield formation stage) and August (ripening stage). The correlations are generally stronger than those for rice and are more pronounced in the elevation range $1,200-1,650 \mathrm{~m}$ amsl. Some variation has been observed in the correlation values in the months of AprilJune (vegetative stage) with longitudes. For instance, during May and June, the correlations are negative between longitudes $85^{\circ} \mathrm{E}$ to $87^{\circ} \mathrm{E}$ and dominantly positive between $87^{\circ} \mathrm{E}$ and $89^{\circ} \mathrm{E}$. However, during yield formation and ripening stages (July and August), the correlations are mostly negative throughout the longitudinal zone. This indicates that higher growing season temperature during the yield formation and ripening stage will have adverse impact on maize yield throughout the region with more pronounced impact in the lower elevations. Compared with the yield of 
2008, estimated change in the maize yield for each degree rise in growing season maximum, minimum and mean temperature varies from -5 to $10 \%,-5$ to $2 \%$ and -4 to $11 \%$, respectively, with notably wide confidence intervals for many of these estimates. We identified monthly maximum and minimum temperature thresholds above which the temperature is negatively correlated with the maize yield as 27 and $18{ }^{\circ} \mathrm{C}$, respectively. Similarly, we identified the monthly mean temperature threshold below which temperature is positively correlated with the maize yield as $22{ }^{\circ} \mathrm{C}$ (Fig. 4), which is within the range of optimum mean temperature $\left(22-25^{\circ} \mathrm{C}\right.$ ) for maize (Singletary et al. 1994; Bannayan et al. 2004). Analysis of the temperature data indicates that below $1,350 \mathrm{~m}$ amsl, growing season maximum and mean temperatures are well above the favorable thresholds of 27 and $22{ }^{\circ} \mathrm{C}$, respectively. Similarly, growing season minimum temperatures exceed the estimated favorable threshold of $18{ }^{\circ} \mathrm{C}$ in the areas below $1,200 \mathrm{~m}$ amsl. In the lower elevation region (particularly below $1,500 \mathrm{~m}$ ), the average monthly temperature during flowering and yield formation stages (June and July) is much higher than the growing season average temperature. Thus, a higher temperature during flowering and yield formation stages in the lower altitudes is expected to have adverse impacts on the maize yield mainly due to shortening of the growing period (White and Reynolds 2003).
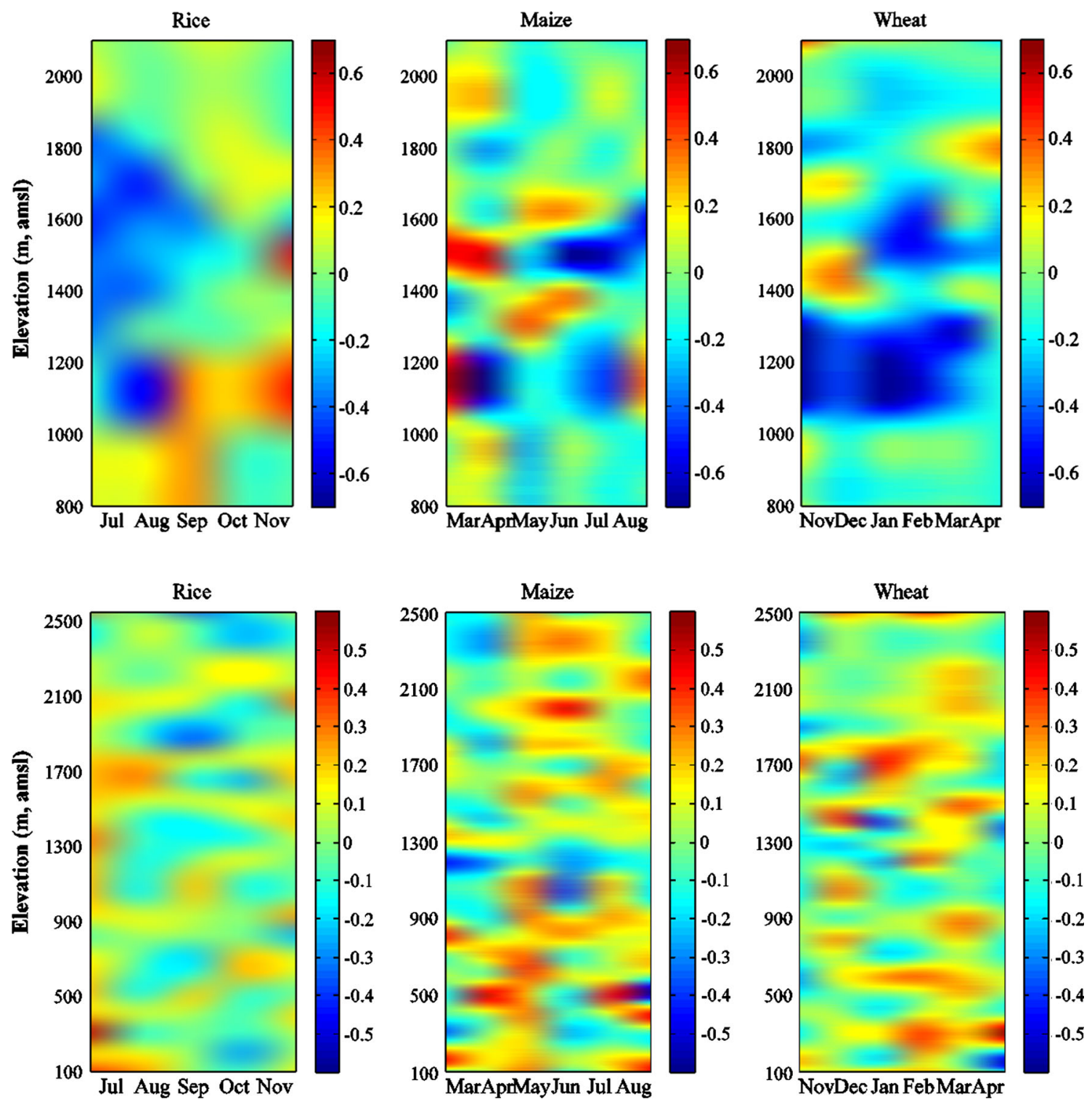

Fig. 2 Pearson correlation coefficients $(r)$ between crop yield and average monthly mean temperature (top) and monthly precipitation (bottom). The correlations are interpolated using the nearest neighborhood method on elevations 

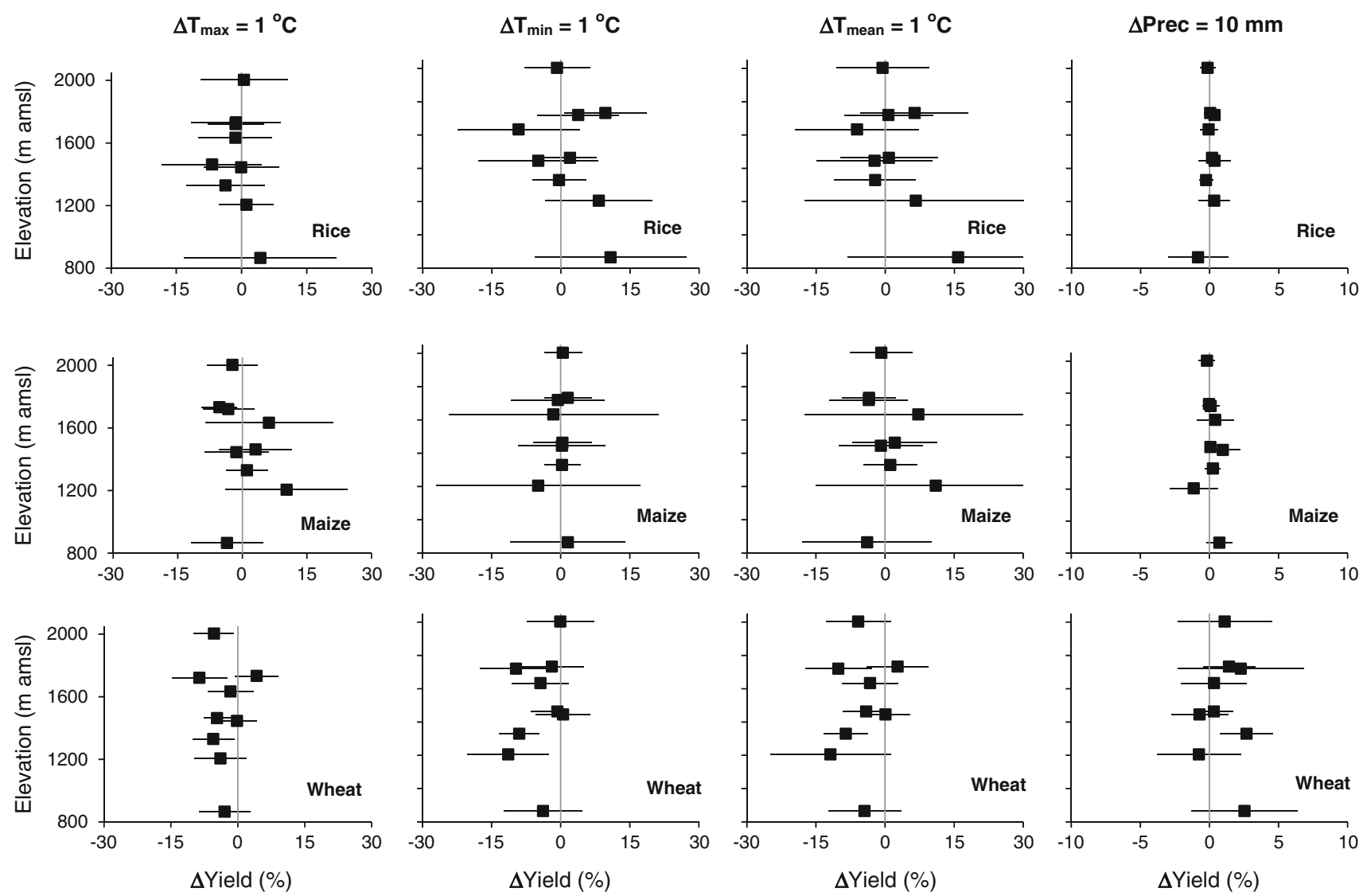

Fig. 3 Sensitivity of crop yields ( $X$-axis; in percentage of respective yields of 2008) to $1^{\circ} \mathrm{C}$ rise in growing season temperature [maximum $(\Delta T \max )$, minimum $(\Delta T \min )$ and mean $(\Delta T$ mean $)]$ and increase in

\section{Wheat}

Wheat yields are mostly negatively correlated with mean monthly temperature. The negative correlations are mostly pronounced at the lower elevations below 1,700 $\mathrm{m}$ and particularly between 1,200 and 1,700 m during NovemberFebruary (vegetation and flowering stages). At the higher elevations (above 1,400 m), some positive but weak correlations are also observed during November and December. The negative correlations are generally stronger than those for rice and maize. Also, the negative correlations between wheat yield and temperature are more pronounced for minimum temperature as compared to the maximum temperature. We did not notice any distinct spatial variation in the temperature-wheat yield relationship with longitudes. Change in yields (compared with the yield of 2008) for one degree rise in growing season maximum, minimum and mean temperature varies from -9 to $4 \%$, -12 to $1 \%$ and -12 to $3 \%$, respectively. Compared with rice and maize, wheat yield has clearly negative response for a positive perturbation $\left(1^{\circ} \mathrm{C}\right.$ rise) in growing season temperature (Fig. 3). Monthly maximum, minimum and

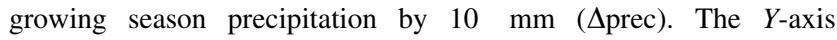
represents elevation $(\mathrm{m}$ amsl) and error bars represent the $95 \%$ confidence interval

mean temperature thresholds above which temperature has negative correlation with wheat yield are identified as 20, 10 and $14{ }^{\circ} \mathrm{C}$, respectively. Experimental studies on several wheat cultivators indicate an optimum mean temperature range of $17-23{ }^{\circ} \mathrm{C}$ (Porter and Gawith 1999). Similarly, the optimum maximum and minimum temperatures for wheat are around 24 and $19{ }^{\circ} \mathrm{C}$, respectively (Asana and Williams 1965; Prasad et al. 2008). In the study region, the growing season maximum, minimum and mean temperatures are above the threshold of 20,10 and $14{ }^{\circ} \mathrm{C}$ in the area below 1,600, 1,500 and 1,700 $\mathrm{m}$ amsl, respectively. Furthermore, in the lower elevations (below $1,700 \mathrm{~m}$ ), the maximum, minimum and mean temperatures in April (ripening stage) are quite above the thresholds. Temperatures higher than the favorable thresholds during the yield formation stage result in reduced yield mainly due to the reduced grain filling duration.

Precipitation-crop yield relationship

Both positive and negative correlations are observed between precipitation and crop yields irrespective of the 

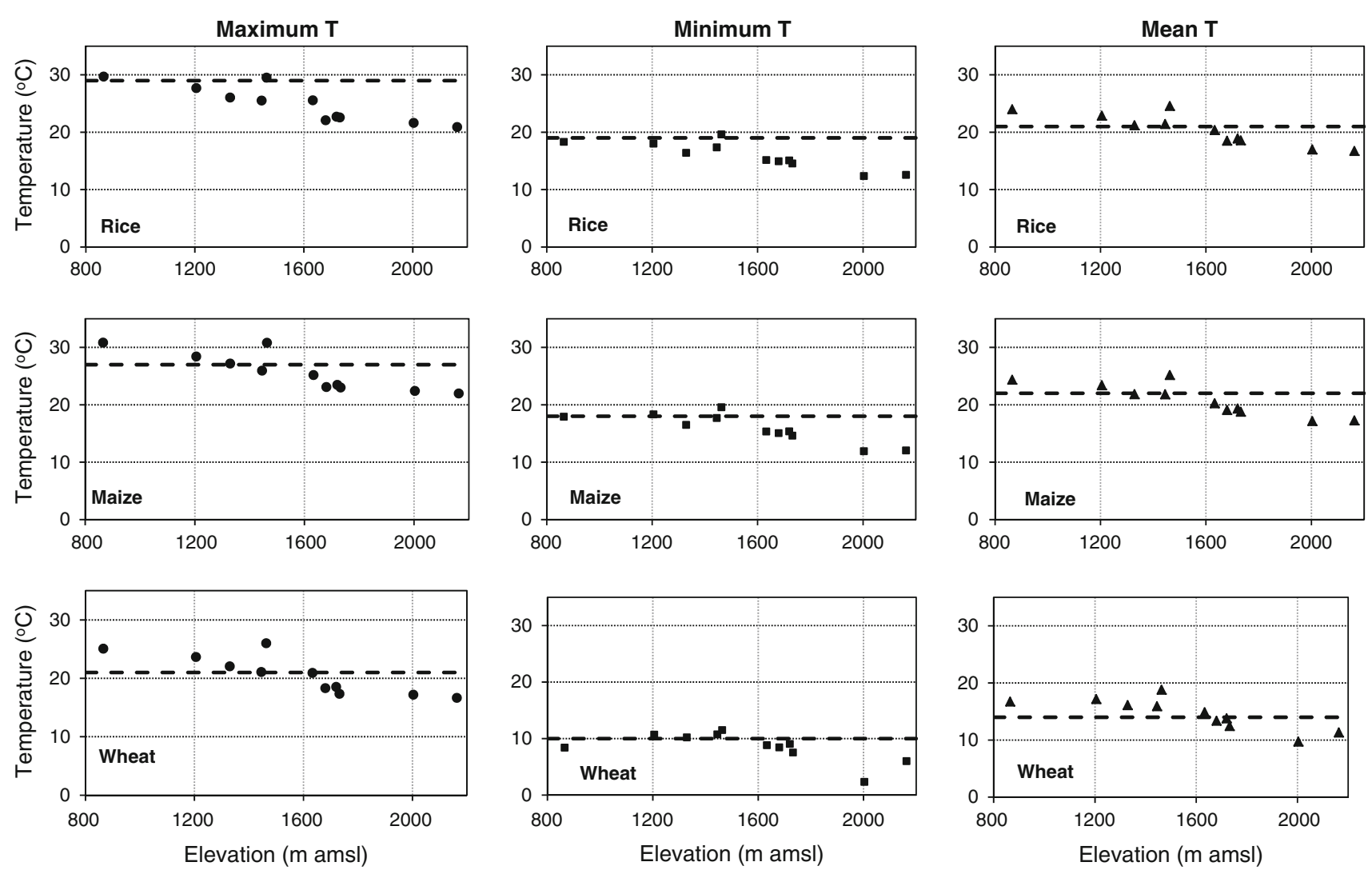

Fig. 4 Average of maximum (left), minimum (middle) and mean (right) temperatures during the growing season for rice (JulyNovember), maize (March-August) and wheat (November-April).

elevation range and growth stages. The correlations are mostly positive for maize and wheat (Fig. 2). Also in most cases, the positive correlations are stronger than the negative correlations except for rice, in which both positive and negative correlations are relatively weak. In Nepal, maize is basically a rain-fed crop, whereas rice and wheat are rain fed as well as irrigated depending on the locations. Being a rain-fed crop, the maize yield shows mostly pronounced correlations followed by wheat and rice with growing season precipitation. For maize, the correlations are dominantly positive in the months of May, July and August, which correspond to the flowering and yield formation stages. Some statistically significant correlations (both positive and negative) are observed particularly at lower elevations below $1,500 \mathrm{~m}$. At higher elevation (above 2,000 m), the correlation values are generally weak. We mainly attribute the weak correlations for rice and wheat to the influence of irrigation as we did not have enough data to treat the irrigated and rain-fed areas separately. Crop yield sensitivities to change in growing season monthly precipitation are mostly positive for all the three crops. The percentage change in yield per $10 \mathrm{~mm}$ increase in growing season precipitation is clearly larger in wheat
The $x$-axis represents the altitude ( $\mathrm{m} \mathrm{amsl)}$ of the temperature stations, and the $y$-axis represents temperature in ${ }^{\circ} \mathrm{C}$. The thick dotted line represents the favorable temperature threshold

than in rice and maize, although with large confidence intervals (Fig. 3).

Impact of climate trends on crop yield

The growing season mean temperatures of all three crops over the last few decades reveal significant warming trends in most parts of the study area (Table S2). However, some significant negative trends in temperatures are also observed. For example, at the elevation around 1,300 and $1,400 \mathrm{~m}$, decrease in the growing season mean temperatures by about $1{ }^{\circ} \mathrm{C}$ per decade is observed in some stations for all three crops during 1987-2008. Both positive and negative trends are particularly high (in some case $>1{ }^{\circ} \mathrm{C}$ per decade) in the elevation range between 1,300 and $1,600 \mathrm{~m}$. The trends in the mean monthly precipitation during the growing seasons of rice and maize are identical and dominantly positive (Table S2). The observed trends in the mean monthly precipitation for the wheat growing season are also mostly positive, but the magnitude of the trend is much smaller than that for rice and maize. However, note that the wheat growing season (NovemberApril), which is largely winter and spring, is a low rainfall 
Fig. 5 Estimated impact of climate trends on yields of rice, maize and wheat. Bars show mean estimated impact due to trends in both temperature and precipitation (overall), error bars show 25th-75th percentiles of the overall impacts (filled square) and (filled circle) represent mean estimated impact due to temperature $(T)$ and precipitation $(P)$ trends, respectively
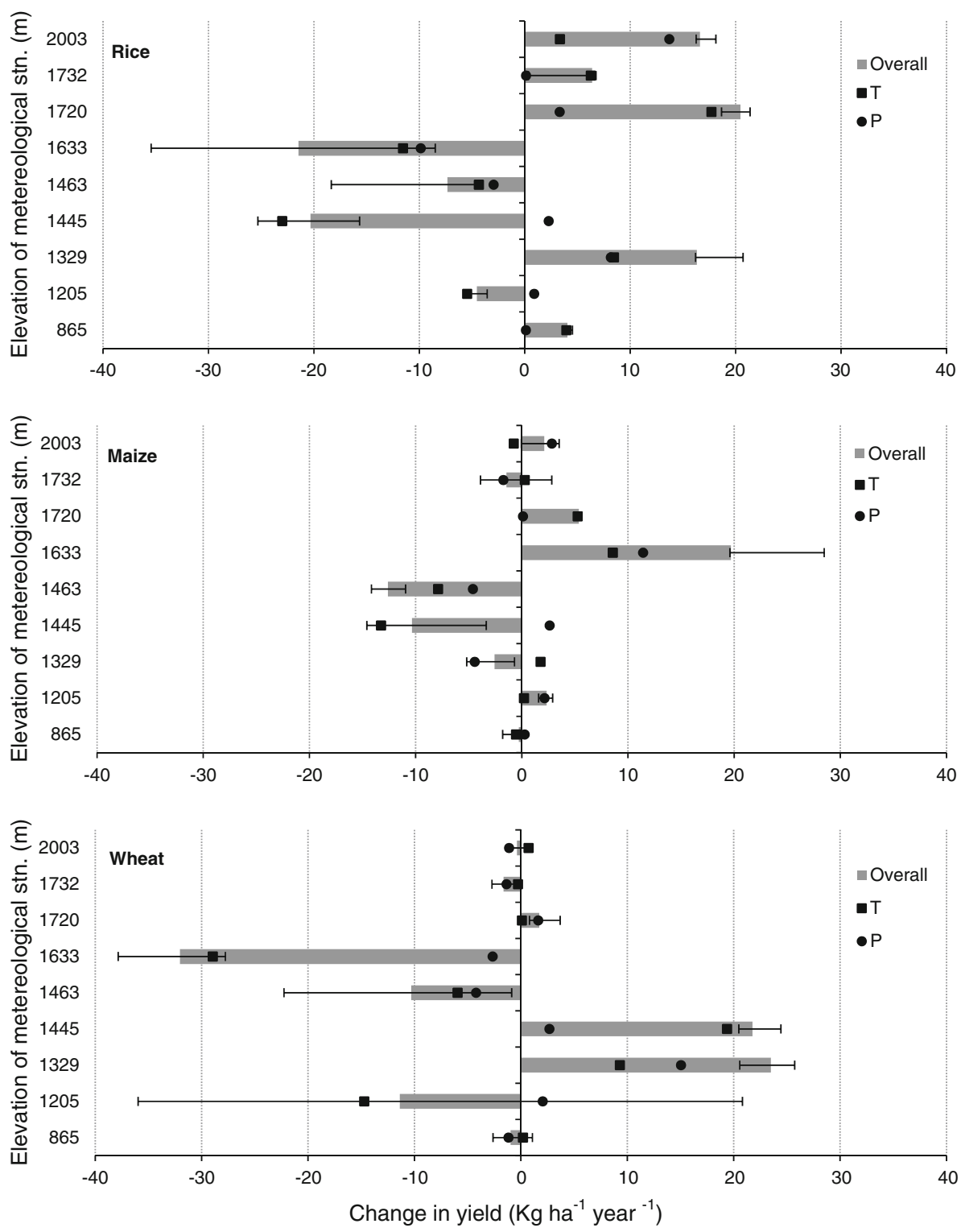

period compared with rice (July-November) and maize (March-August) growing seasons. Therefore, the trend magnitudes relative to the mean rainfall over the seasons are comparable to each other for all three crops.

In Fig. 5, the impacts of trends in climatic variables on rice, maize and wheat yields are presented. The results indicate that the increasing temperature trend has mostly suppressed the crop yields particularly in the area below about $1,600 \mathrm{~m}$ with most pronounced impact on wheat yield. However, at some higher altitudes, warming leads to increase in rice and maize yields with more pronounced impacts on rice. For example, at the elevation around $1,700 \mathrm{~m}$, rice and maize yields increased at the rate of 17.7 and $5.2 \mathrm{~kg} \mathrm{ha}^{-1}$ year $^{-1}$, respectively, due to the increase in growing season mean temperature by $0.42{ }^{\circ} \mathrm{C}$ decade $^{-1}$ for rice and $0.30{ }^{\circ} \mathrm{C}$ decade $^{-1}$ for maize during 1968-2008.
Generally, increasing precipitation trends show a gain in crop yields. However, negative impacts of increasing precipitation trends are also detected on maize yields at some locations with relatively higher growing season precipitation. This shows that the increase in precipitation up to a certain level is likely to increase the yield. Any further increase in precipitation will likely have a negative impact on crop yields. In the majority of the instances, the impacts on yield are mainly determined by the temperature trends rather than precipitation trends. As seen in Fig. 5, the overall impact is closer to the impact due to trends in temperature. We used confidence intervals to represent uncertainty of the regression models in the estimation of impacts on yields. Generally, the estimated impacts of precipitation trends have higher uncertainty compared with that of the impacts of temperature trends. 
Limitations

The crop production data are available only at a district level, and this restricted us to account for the variation of crop seasons within a district, variation of threshold temperature for different elevations and separation of irrigated and rain-fed areas. However, previous studies have shown that even such aggregated data (e.g., at district or country level) can be sufficient to establish climate-crop yield relationships and to assess the impact of climate trends on crop production (e.g., Lobell et al. 2007; 2008, 2011; Tao et al. 2008). The relatively weaker relationship observed between crop yield and precipitation, particularly for rice, is attributed to the impact of irrigation. Separating irrigated and rain-fed crops could also reduce the uncertainty range in the estimation of impacts (Fig. 5).

The use of monthly averaged climate data did not allow us to explicitly consider the influence of extreme events (such as heat waves and floods). Such events can lead to dramatic reductions in crop yield particularly when they coincide with critical phases of crop development (Porter and Semenov 2005). For example, the literature has indicated that temperature $>30{ }^{\circ} \mathrm{C}$ for period more than $8 \mathrm{~h}$ can reduce grain set in wheat (Porter and Semenov 2005) and temperature $>35{ }^{\circ} \mathrm{C}$ lasting for more than just $1 \mathrm{~h}$ can lead to pollen sterility in rice resulting in reduced yield (Slingo et al. 2005; Wheeler et al. 2000). Nonetheless, our regression model presents relatively accurate estimation of the crop yield with more than $70 \%$ of yield variance explained for all the three crops (as indicated by $R^{2}$ values).

To achieve food security under climate change, it is important to sustain or enhance both crop yield and its stability. Here, we evaluated impacts of climate in terms of total gain or loss in crop yields. Some studies have shown that crop yields are likely to be more volatile with increase in climate variability under future climatic condition (see, e.g., Urban et al. 2012). Therefore, some potential benefits of climate change in total crop production may be countered by the increased year-to-year variability, leading to instability of long-term food supply.

We limited our study to the impact of climate trends on crop production only. An extension of our results to the level of social and economic indices, such as change in farm incomes, could be an interesting study. However, our study provides useful information that the higher the magnitude of negative impacts of historical climate on crop yields, the faster the adaptation measures have to be implemented to offset the yield loss.

\section{Conclusions}

Rice, maize and wheat grown at altitudes below 1,100 , 1,350 and $1,700 \mathrm{~m}$ amsl, respectively, are already under temperature stress in the study area, particularly during flowering and yield formation stages of crop growth. Increasing temperature trends show mostly negative impacts on these crop yields except at some high altitudes. If the observed trends in temperature continue in future, the impacts are likely to be mostly negative on crop production in the basin. However, crop production may gain from the warming at relatively higher altitudes (mainly rice and maize) provided other conditions, such as water availability, soil fertility, etc., are favorable.

Climate conditions during the flowering and yield formation stages of crop growth impact crop yields considerably. Relatively inexpensive adaptation measures such as change in planting dates to avoid higher temperature stress during the flowering and grain filling stages can reduce the adverse impact on crop yields due to climate change. Similarly, management strategies such as, crop rotation, use of improved crop varieties and increased irrigated agriculture are expected to help minimize the risk associated with yield variability under future climatic conditions. Additionally, in the future, farmers may tend to grow crops at higher altitudes as a positive impact of warming.

It is expected that by $2090 \mathrm{~s}$, average temperature in Nepal will increase by 3.0 to $6.3{ }^{\circ} \mathrm{C}$ with a multi-model mean of $4.7^{\circ} \mathrm{C}$ (NCVST 2009). Despite underlying uncertainty, such projected rise in temperature is generally expected to amplify the estimated adverse impacts on crop production and add pressure to the food supply. In the country such as Nepal where 46 out of 75 districts experience food deficit (CBS 2003) and $60 \%$ of the farm households produce food that is sufficient for less than 6 months (CBS 2006), reduction in crop production in one of the largest and ecologically diverse basins will worsen the food security at the national level.

Acknowledgments This study was funded as a part of AGloCAP (Adaptation to Global Changes in Agricultural Practices) project by the Netherlands Ministry of Development Cooperation (DGIS) through the UNESCO-IHE Partnership Research Fund (UPaRF). The authors would like to thank the Department of Hydrology and Meteorology (DHM) and Department of Agriculture (DOA), Nepal, for providing meteorological and crop production data, respectively.

Open Access This article is distributed under the terms of the Creative Commons Attribution License which permits any use, distribution, and reproduction in any medium, provided the original author(s) and the source are credited.

\section{References}

Arnell NW, Cannell MGR, Hulme M, Kovats RS, Mitchell JFB, Nicholls RJ, Parry ML, Livermore MTJ, White A (2002) The consequences of $\mathrm{CO}_{2}$ stabilisation for the impacts of climate change. Clim Chang 53:413-446 
Asana RD, Williams RF (1965) The effect of temperature stress on grain development in wheat. Aust J Agric Res 16(1):1-13

Babel MS, Agarwal A, Swain DK, Herath S (2011) Evaluation of climate change impacts and adaptation measures for rice cultivation in Northeast Thailand. Clim Res 46:137-146

Baker JT, Allen LH Jr (1993) Contrasting crop species responses to $\mathrm{CO}_{2}$ and temperature: rice, soybean, and citrus. Vegetatio 104(105):239-260

Bannayan M, Hoogenboom G, Crout NMJ (2004) Photothermal impact on maize performance: a simulation approach. Ecol Model 180:277-290

Berg A, de Noblet-Ducoudré N, Sultan B, Lengaigne M, Guimberteau M (2012) Projections of climate change impacts on potential C4 crop productivity over tropical regions. Agric For Meteorol. doi:10.1016/j.agrformet.2011.12.003

Boote KJ, Allen LH, Prasad VVP, Baker JT, Gesch RW, Snyder AM, Pan D, Thomas JMG (2005) Elevated temperature and $\mathrm{CO}_{2}$ impacts on pollination, reproductive growth, and yield of globally important crops. J Agric Meteorol 60(5):469-474

CBS (Central Burro of Statistics) (2003) Agricultural Statistics of Nepal, 2000/2003, CBS, NPC, HMG of Nepal, Kathmandu

CBS (Central Burro of Statistics) (2006) Resiliency amidst conflict. Poverty assessment in Nepal 1995-1996 and 2003-2004. Central Burro of Statistics, Kathamndu

Gautam JC (2008) Country report on the state of the Nepal's plant genetic resources for food and agriculture. http://www.fao.org/ docrep/013/i1500e/Nepal.pdf. Accessed 28 Nov 2011

Ghimire R, Adhikari KR, Chen ZS, Shah SC, Dahal KR (2011) Soil organic carbon sequestration as affected by tillage, crop residue, and nitrogen application in rice-wheat rotation system. Paddy Water Environ, doi:10.1007/s10333-011-0268-0

Haffner W (1984) Potentials and limits of agricultural production in Nepal as seen from an ecological-geographical standpoint. Erdwissenschaftliche Forschung XVIII:115-126

Hu Y, Maskey S, Uhlenbrook S (2011) Trends in temperature and rainfall extremes in the Yellow River source region, China. Clim Chang 110:403-429

Hu Y, Maskey S, Uhlenbrook S (2013) Expected changes in future temperature extremes and their elevation dependency over the Yellow River source region. Hydrol Earth Syst Sci 17:2501-2514

IPCC (Intergovernmental Panel on Climate Change) (2007a) Climate change 2007: the physical science basis. In: Solomon S, Qin D, Manning M, Chen Z, Marquis M, Averyt KB, Tignor M, Miller HL (eds) Contribution of working group I to the fourth assessment report of the intergovernmental panel on climate change. Cambridge University Press, Cambridge

IPCC (Intergovernmental Panel on Climate Change) (2007b) Climate change 2007: impacts, adaptation and vulnerability. Summary for policy makers. http://www.ipcc.cg/SPM13apr07.pdf

Lobell DB, Field CB (2007) Global scale climate-crop yield relationships and the impacts of recent warming. Environ Res Lett 2:014002. doi:10.1088/1748-9326/2/1/014002

Lobell DB, Ortiz-Monasterio JI, Asner GP, Matson PA, Naylor RL, Falcon WP (2005) Analysis of wheat yield and climatic trends in Mexico. Field Crops Res 94:250-256

Lobell DB, Cahill K, Field C (2007) Historical effects of temperature and precipitation on California crop yields. Clim Chang 81:187-203

Lobell DB, Burke MB, Tebaldi C, Mastrandrea MD, Falcon WP, Naylor RL (2008) Prioritizing climate change adaptation needs for food security in 2030. Science 319:607-610

Lobell DB, Schlenker W, Costa-Roberts J (2011) Climate trends and global crop production since 1980. Science 333:616-620

Luo Q, Bellotti W, Williams M, Wang E (2009) Adaptation to climate change of wheat growing in South Australia: analysis of management and breeding strategies. Agric Ecosyst Environ 129:261-267

Manandhar DN, Shakya DM (1996) Climate and crops of Nepal. Nepal Agriculture Research Council and Swiss Agency for Development and Cooperation, Nepal

Maskey S, Uhlenbrook S, Ojha S (2011) An analysis of snow cover changes in the Himalayan region using MODIS snow products and in situ temperature data. Clim Chang 108:391-400

Morton JF (2007) The impact of climate change on smallholder and subsistence agriculture. Proc Natl Acad Sci USA 104:19680-19685

NARC (Nepal Agricultural Research Council) (2010) NARC's Strategic Vision for Agricultural Research (http://www.narc. org.np/narc_vision/NARC_vision.pdf)

Nayava JL, Singh R, Bhatta MR (2009) Impact of climate, climate change and modern technology on wheat production in Nepal: a case study at Bhairahawa. J Hydrol Meteorol 6(1):1-13

NCVST (Nepal Climate Vulnerability Study Team (2009) Vulnerability through the eyes of vulnerable: climate change induced uncertainties and Nepal's development predicaments. ISET-N, and Boulder, (Colorado) ISET for Nepal Climate Vulnerability Study Team (NCVST), Kathmandu

Nicholls N (1997) Increased Australian wheat yield due to recent climate trends. Nature 387:484-485

Parry ML, Rosenzweig C, Iglesias A, Livermore M, Fischer G (2004) Effects of climate change on global food production under SRES emissions and socio-economic scenarios. Glob Environ Chang 14:53-67

Paudyal KR, Ransom JK, Rajbhandari NP, Adhikari K, Gerpacio RV, Pingali PL (2001) Maize in Nepal: production systems, constraints, and priorities for research. NARC and CIMMYT, Kathmandu

Peng S, Huang J, Sheehy JE, Laza RC, Visperas RM, Zhong X, Centeno GS, Khush GS, Cassman KG (2004) Rice yields decline with higher night temperature from global warming. Proc Natl Acad Sci USA 101:9971-9975

Porter JR, Gawith M (1999) Temperatures and the growth and development of wheat: a review. Eur J Agron 10:23-36

Porter JR, Semenov MA (2005) Crop responses to climatic variation. Philos Trans R Soc B 360(1463):2021-2038

Prasad PVV, Pisipati SR, Ristic Z, Bukovnik V, Fritz AK (2008) Impact of night time temperature on physiology and growth of spring wheat. Crop Sci 48:2372-2380

Rosenzweig C, Iglesias A (1994) Implications of climate change for international agriculture: crop modeling study. US Environmental Protection Agency, Washington, DC

Rowhani P, Lobell DB, Linderman M, Ramankutly N (2011) Climate variability and crop production in Tanzania. Agric For Meteorol 151:449-460

Sharma K, Khanal SN (2010) A review and analysis of existing legal and policy issues related to land tenure and agriculture in Nepal. Kathmandu Univ J Sci Eng Technol 6(ii):133-141

Sharma E, Chettri N, Tse-ring K, Shrestha AB, Fang J, Mool P, Eriksson M (2009) Climate change impacts and vulnerability in the Eastern Himalayas. ICIMOD, Kathmandu

Shrestha AB, Wake CP, Mayewski PA, Dibb JE (1999) Maximum temperature trends in the Himalaya and its vicinity: an analysis based on temperature records from Nepal for the period 1971-94. J Clim 12:2775-2787

Singletary GW, Banisadr R, Keeling PL (1994) Heat stress during grain filling in maize: effects on Carbohydrate storage and metabolism. Aust J Plant Physiol 21(6):829-841

Slingo JM, Challinor AJ, Hoskins BJ, Wheeler TR (2005) Introduction: food crops in changing climate. Philos Trans R Soc B 360:1983-1989

Tao F, Zhang Z (2010) Adaptation of maize production to climate change in North China Plain: quantify the relative contributions of adaptation options. Eur J Agron 33:103-116 
Tao F, Yokozawa M, Liu J, Zhang Z (2008) Climate-crop yield relationship at provincial scales in China and the impact of recent climate trends. Clim Res 38:83-94

Urban D, Roberts MJ, Schlenker W, Lobell DB (2012) Projected temperature changes indicate significant increase in interannual variability of US maize yields. Clim Chang 112(2):525-533

Wheeler TR, Craufurd PQ, Ellis RH, Porter JR, Prasad PVV (2000) Temperature variability and the yield of annual crops. Agric Ecosyst Environ 82:159-167
White JW, Reynolds MP (2003) A physiological perspective on modeling temperature response in wheat and maize crops. In: Proceedings of a Workshop, CIMMYT, El Batán, Mexico, 23-25 April, 2001. NRG-GIS Series 03-01, México, D.F, CIMMYT

World Bank (2009) Nepal: priorities for agriculture and rural development. http://go.worldbank.org/D9M3ORHVL0. Accessed 20 Aug 2013 